Review

\title{
Relationship between depression and frailty in older adults: A systematic review and meta-analysis
}

\author{
Pinar Soysal ${ }^{a}$, Nicola Veronese ${ }^{\text {b,c }}$, Trevor Thompson ${ }^{d}$, Kai G. Kahl ${ }^{\text {e }}$, Brisa S. Fernandes ${ }^{\text {f,g }}$, \\ A. Matthew Prina ${ }^{\mathrm{h}}$, Marco Solmi ${ }^{\mathrm{c}, \mathrm{i}, \mathrm{j}}$, Patricia Schofield ${ }^{\mathrm{k}}$, Ai Koyanagi ${ }^{\mathrm{l}, \mathrm{m}}$, Ping-Tao Tseng ${ }^{\mathrm{n}}$, \\ Pao-Yao Lin ${ }^{\mathrm{o}, \mathrm{p}}$, Che-Sheng Chu ${ }^{\mathrm{q}}$, Theodore D. Cosco ${ }^{\mathrm{r}, \mathrm{s}}$, Matteo Cesari ${ }^{\mathrm{t}, \mathrm{u}}$, \\ Andre F. Carvalho ${ }^{\mathrm{v}}$, Brendon Stubbs ${ }^{\mathrm{h}, \mathrm{k}, \mathrm{w}, *}$
}

\footnotetext{
a Kayseri Education and Research Hospital, Geriatric Center, Kayseri, Turkey

b National Research Council, Neuroscience Institute, Aging Branch, Padova, Italy

${ }^{\mathrm{c}}$ Institute of Clinical Research and Education in Medicine (IREM), Padova, Italy

d Faculty of Education and Health, University of Greenwich, London, United Kingdom

e Department of Psychiatry, Social Psychiatry and Psychotherapy, Hannover Medical School, Carl-Neuberg-Str. 1, 30625 Hannover, Germany

${ }^{\mathrm{f}}$ IMPACT Strategic Research Centre, Deakin University School of Medicine, and Barwon Health, Geelong, VIC, Australia

${ }^{g}$ Laboratory of Calcium Binding Proteins in the Central Nervous System, Department of Biochemistry, Federal University of Rio Grande do Sul, Porto Alegre,

Brazil

${ }^{\mathrm{h}}$ Health Service and Population Research Department, Institute of Psychiatry, Psychology and Neuroscience, King's College London, De Crespigny Park, London, Box SE5 8AF, United Kingdom

${ }^{i}$ Department of Neurosciences, University of Padova, Padova, Italy

${ }^{\mathrm{j}}$ Local Health Unit 17, Mental Health Department, Padova, Italy

${ }^{\mathrm{k}}$ Faculty of Health, Social Care and Education, Anglia Ruskin University, Chelmsford, United Kingdom

${ }^{1}$ Research and Development Unit, Parc Sanitari Sant Joan de Déu, Universitat de Barcelona, Fundació Sant Joan de Déu, Dr. Antoni Pujadas, 42, Sant Boi de Llobregat, Barcelona 08830, Spain

m Instituto de Salud Carlos III, Centro de Investigación Biomédica en Red de Salud Mental, CIBERSAM, Monforte de Lemos 3-5 Pabellón 11, Madrid 28029,

Spain

${ }^{n}$ Department of Psychiatry, Tsyr- Huey Mental Hospital, Kaohsiung Jen-Ai's Home, Taiwan

${ }^{\circ}$ Department of Psychiatry, Kaohsiung Chang Gung Memorial Hospital and Chang Gung University College of Medicine, Kaohsiung City, Taiwan

p Institute for Translational Research in Biomedical Sciences, Kaohsiung Chang Gung Memorial Hospital, Kaohsiung, Taiwan

${ }^{\mathrm{q}}$ Kaohsiung Veterans General Hospital, Kaohsiung City, Taiwan

${ }^{\mathrm{r}}$ MRC Unit for Lifelong Health and Ageing at UCL, 33 Bedford Place, London WC1 B5JU, United Kingdom

${ }^{s}$ Oxford Institute of Population Ageing, University of Oxford, 66 Banbury Road, Oxford, OX2 6PR, United Kingdom

${ }^{\mathrm{t}}$ Inserm UMR1027, Université de Toulouse III Paul Sabatier, Toulouse, France

u Gérontopôle, Centre Hospitalier Universitaire de Toulouse, Toulouse, France

${ }^{\vee}$ Translational Psychiatry Research Group and Department of Clinical Medicine, Faculty of Medicine, Federal University of Ceará, Fortaleza, CE, Brazil

w Physiotherapy Department, South London and Maudsley NHS Foundation Trust, Denmark Hill, London SE5 8AZ, United Kingdom
}

\section{A R T I C L E I N F O}

\section{Article history:}

Received 2 February 2017

Received in revised form 7 March 2017

Accepted 21 March 2017

Available online 31 March 2017

\section{Keywords:}

Depression

Frail

Geriatrics

Older adults

Meta-analysis

Psychiatry

\begin{abstract}
A B S T R A C T
Aim: Depression and frailty are prevalent and burdensome in older age. However, the relationships between these entities are unclear and no quantitative meta- analysis exists. We conducted a systematic review and meta-analysis to investigate the associations between depression and frailty. Methods: Two authors searched major electronic databases from inception until November-2016 for cross-sectional/longitudinal studies investigating depression and frailty. The strength of the reciprocal associations between frailty and depression was assessed through odds ratios (ORs) adjusted for potential confounders.

Results: From 2306 non duplicated hits, 24 studies were included. The overall prevalence of depression in 8023 people with frailty was $38.60 \%\left(95 \%\right.$ CI $\left.30.07-47.10, \mathrm{I}^{2}=94 \%\right)$. Those with frailty were at increased odds of having depression (OR adjusted for publication bias 4.42, 95\%CI 2.66-7.35, $\mathrm{k}=11$ ), also after adjusting for potential confounders (OR=2.64; $\left.95 \% \mathrm{CI}: 1.59-4.37, \mathrm{I}^{2}=55 \%, \mathrm{k}=4\right)$. The prevalence of frailty in 2167 people with depression was $40.40 \%$ (95\%CI 27.00-55.30, $\mathrm{I}^{2}=97 \%$ ). People with depression were at increased odds of having frailty $(\mathrm{OR}=4.07,95 \% \mathrm{CI} 1.93-8.55, \mathrm{k}=8)$. The pooled $\mathrm{OR}$ for incident frailty, adjusted for a median of 7 confounders, was $3.72\left(95 \% \mathrm{CI} 1.95-7.08, \mathrm{I}^{2}=98 \%, \mathrm{k}=4\right)$, whilst in two studies frailty increased the risk of incident depression with an $\mathrm{OR}=1.90\left(95 \% \mathrm{CI} 1.55-2.32, \mathrm{I}^{2}=0 \%\right)$.
\end{abstract}

\footnotetext{
* Corresponding author at: Physiotherapy Department, South London and Maudsley NHS Foundation Trust, Denmark Hill, London, United Kingdom.

E-mail address: brendon.stubbs@kcl.ac.uk (B. Stubbs).
} 
Conclusion: This meta-analysis points to a reciprocal interaction between depression and frailty in older adults. Specifically, each condition is associated with an increased prevalence and incidence of the other, and may be a risk factor for the development of the other. However, further prospective investigations are warranted.

(c) 2017 Elsevier B.V. All rights reserved.

\section{Contents}

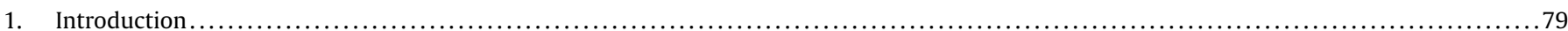

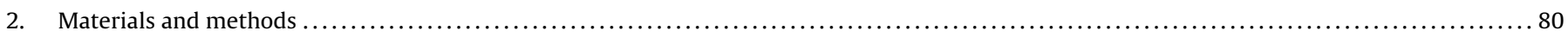

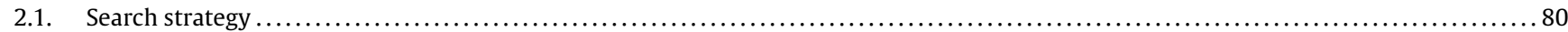

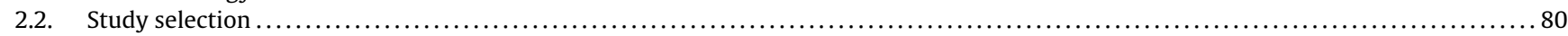

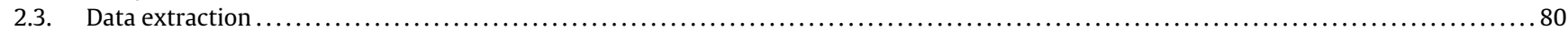

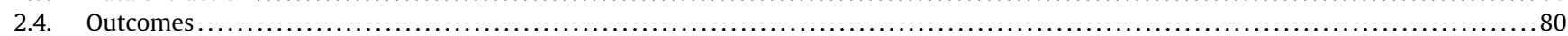

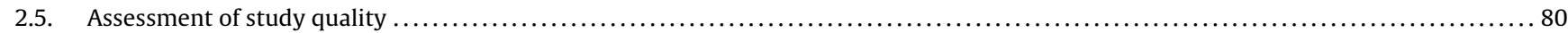

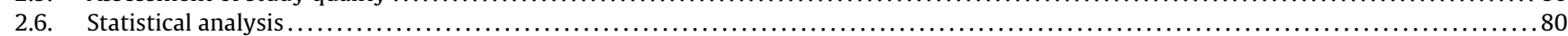

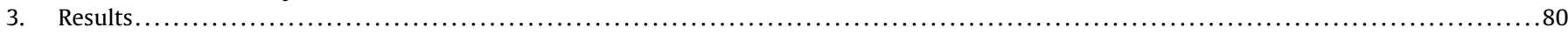

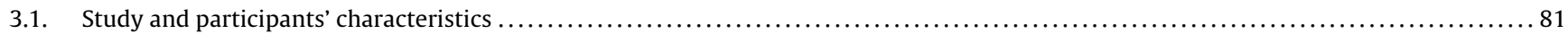

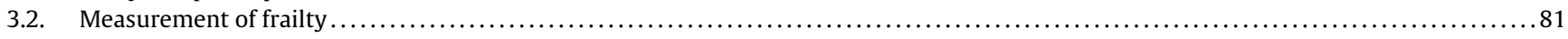

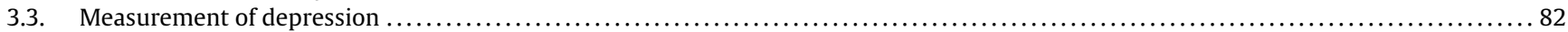

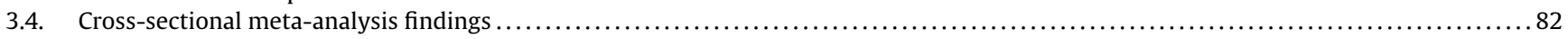

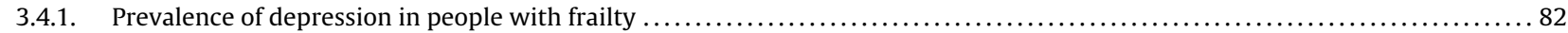

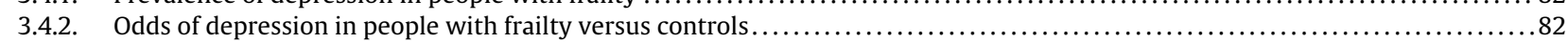

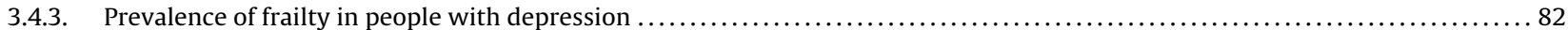

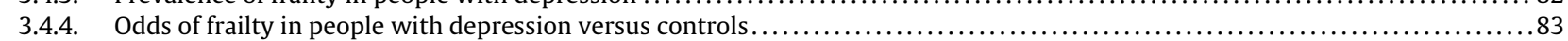

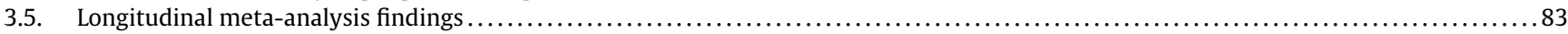

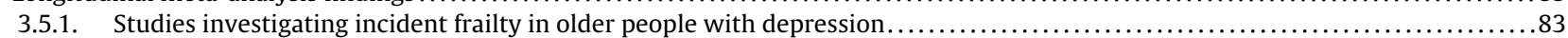

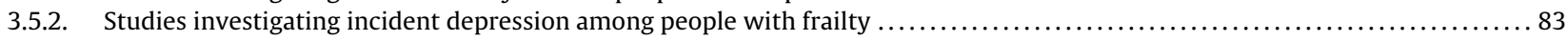

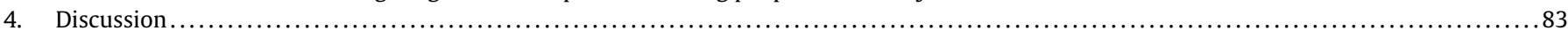

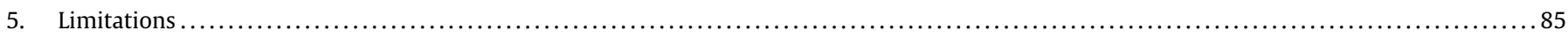

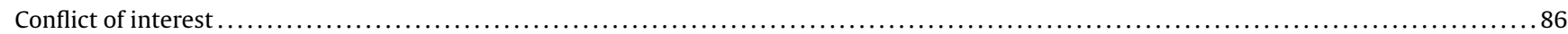

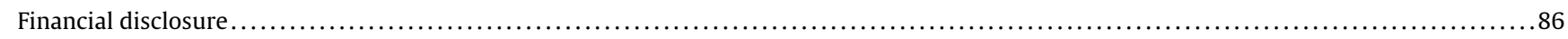

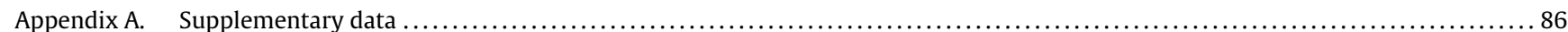

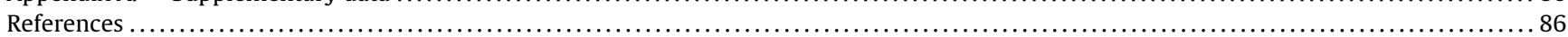

\section{Introduction}

Frailty and depression are two common and pervasive medical conditions among older adults. The prevalence of depression in older age ranges from 10 to $20 \%$ (Rodda et al., 2011) and the prevalence of frailty is estimated to be similar (Collard et al., 2012). Recent studies have suggested that $16-35 \%$ of frail individuals have also experienced co-existing depression, and that the prevalence of depression in frail individuals is as high as $46.5 \%$ in older adults (Buigues et al., 2015). Both depression and frailty are associated with a range of deleterious outcomes in older age such as lower quality of life (QOL), increased use of healthcare services, increased morbidity and mortality (Clegg et al., 2013; Fugate Woods et al., 2005; Hare et al., 2014; Rodda et al., 2011). Furthermore, co-existing depression and frailty is associated with particularly worse outcomes such as accelerated cognitive impairment and disability (Potter et al., 2016). There are several reasons that may account for the high levels of commorbidity between depression and frailty. One is the overlap in some areas of diagnostic criteria, e.g. unintentional weight loss, making it difficult to distinguish from each other, particularly with advancing age. Another factor is that depression and frailty have some common etiology that makes disentanglement difficult (Brown et al., 2014). Given the high levels of depression (Buigues et al., 2015) and frailty (Soysal et al., 2016) in older age and the deleterious outcomes when they co-exist, understanding the relationship between these factors is of utmost importance.

Despite the public health importance, the prevalence and incidence of depression among people with frailty and the opposite relationship is largely unknown. The convergence of the frailty and depression spectrum in mid- and late-life also give rise to the hypothesis of 'overlapping syndromes' (Katz, 2004), with possible biological mechanisms accounting for both syndromes (Vaughan et al., 2015). Most evidence to date suggests that the frailty and depression criteria consist of a highly overlapping but distinct subpopulation (Mezuk et al., 2013); moreover, the association between the two constructs cannot be fully explained by the overlapping of their symptoms (Lohman, 2013) so frailty and depression must be considered interrelated rather than overlapping syndromes. To date, previous narrative and/or selective reviews have suggested there may be a relationship between frailty and depression (Brown et al., 2016; Buigues et al., 2015; Mezuk et al., 2012; Benraad et al., 2016; Drey et al., 2011). For instance, one previous narrative systematic review (Vaughan et al., 2015) suggested that the co-occurrence of depression and frailty was greater than $10 \%$ in older adults $\geq 55$ years old, but noted that there is considerable variation in the estimates and a meta-analysis was not conducted. To date, to the best of our knowledge, no meta-analysis has been conducted to consider the relationship between depression and frailty.

Given the aforementioned, we conducted a systematic review and meta-analysis to investigate 1 ) the prevalence and odds of depression in people with frailty, 2) the prevalence and odds of frailty in people with depression, 3 ) the incidence of depression in people with frailty, and 4) the incidence of frailty in people with depression. 


\section{Materials and methods}

This systematic review was conducted according to the Strengthening the Reporting of Observational Studies in Epidemiology [STROBE] criteria (von Elm et al., 2008) and the recommendations in the Preferred Reporting Items for Systematic Reviews and Meta-Analyses [PRISMA] statement (Liberati et al., 2009). The review followed a predetermined, but unpublished protocol.

\subsection{Search strategy}

Two independent authors (BS and NV) searched Medline (via Ovid), Psychinfo and EMBASE for studies from inception until $11 / 2016$ with no language restrictions. The search terms used were (frailty or frail*) and (depress* or depressive or major depressive disease). Conference abstracts were also included and the authors were contacted for obtaining missing information at least two times in a month.

\subsection{Study selection}

Included studies were published quantitative studies of a cross sectional or longitudinal design that: (1) Reported the prevalence or incidence of frailty <-----> depression in older adults with a mean age over 60 years and older; (2) Captured frailty with a recognized criteria (e.g. Fried's criteria (Fried et al., 2001)); (3) Captured depression according to structured interview diagnostic criteria (e.g. DSM and major depressive disorder (MDD)) or depressive symptoms with a validated depression screening measure (e.g. Center for Epidemiologic Studies Depression Scale (CES-D) (Radloff, 1977)) (henceforth called 'depression', although where possible in the results we differentiate between MDD and depressive symptoms); and (4) included a control group (pre-frail and robust as separate entities or together).

Studies were excluded if they (1) did not use a clear diagnostic criteria for frailty or only used one item for its diagnosis (e.g. low gait speed) or (2) reported depression with an unvalidated screening tool or measure.

\subsection{Data extraction}

Two authors (NV, PS) independently extracted data from the selected studies in a standardized Microsoft Excel spreadsheet. Any disagreement was resolved by consensus with a third author (BS). The following information was extracted: 1) characteristics of the study population (e.g. sample size, demographics, country in which the study was performed); 2) setting in which the study was performed; 3) diagnostic criteria for frailty and depression; 4) demographic characteristics (mean age and percentage of women) by frailty and depression status; 5 ) type and number of adjustments in the multivariate analyses (for longitudinal studies); 6) follow-up period (only for longitudinal studies).

If we required additional data to either confirm or enable study inclusion, we contacted the primary authors up to three times over a month period.

\subsection{Outcomes}

The primary outcomes were a) the prevalence and comorbid odds of depression/depressive symptoms in frailty and b) the prevalence and comorbid odds of frailty in people with depression/depressive symptoms. In addition, we calculated the incidence of c) depression/depressive symptoms onset in people with frailty, and d) frailty onset in people with depression/depressive symptoms.

\subsection{Assessment of study quality}

Study quality was assessed by two investigators (PS, BS) using the Newcastle-Ottawa Scale (NOS) (Wells et al., 2012). A third reviewer was available for mediation (NV). The NOS assigns a maximum of 9 points based on three quality parameters: selection, comparability, and outcome (Wells et al., 2012).

\subsection{Statistical analysis}

Analyses were performed by two independent investigators (BS, NV) using Comprehensive Meta-Analysis (CMA) 3 (http://www. meta-analysis.com). Due to the anticipated heterogeneity, a random effects meta-analysis was undertaken. The analyses were conducted in the following steps. First, the prevalence of depression among people with frailty together with 95\% confidence intervals (CIs) was calculated. Second, the odds ratio and $95 \% \mathrm{CI}$ of frailty among people with and without depression was calculated. Third, the prevalence of frailty among people with depression and $95 \% \mathrm{CI}$ was calculated. Fourth, the odds ratio and 95\% CI of frailty among people with and without depression was calculated. For each of the above analyses, when possible, we conducted subgroup analyses investigating differences according to geographical region, study setting, depression classification (structured clinical assessment versus screening measure) and frailty measure (e.g. Fried criteria versus others) (Fried et al., 2001). Where available, adjusted estimates of the association between frailty and depression (or the contrary) were extracted and pooled as ORs. Finally, ORs adjusted for the maximum number of covariates available for each study were used to assess the association between frailty (or depression) at the baseline and incident depression (or frailty) at follow-up.

Study heterogeneity was measured using the Cochran's Q and I-squared statistics, assuming that $\mathrm{a} p \leq 0.10$ for the former and a value $\geq 50 \%$ for the latter indicated a significant and substantial heterogeneity (Higgins and Thompson, 2002). Given significant heterogeneity, a meta-regression analysis was performed using differences in mean age, body mass index (BMI) and percentage of females among groups (frail, pre-frail, robust) as moderators in single meta regression. Publication bias was assessed by visually inspecting funnel plots, and to account for publication bias, we used the Duval and Tweedie trim-and-fill method (Duval and Tweedie, 2000), based on the assumption that the effect sizes of all the studies are normally distributed around the center of a funnel plot; in the event of asymmetries, it adjusts for the potential effect of unpublished studies.

\section{Results}

The search identified 2306 non-duplicated potentially eligible studies. Following a detailed review of title and abstracts, a total of 63 full text articles were reviewed. The eligibility criteria were applied and 39 articles were excluded (reasons summarized in Fig. 1) with a total of 24 articles meeting the inclusion criteria (Almeida et al., 2016, 2015; Matheus et al., 2016; Badalà et al., 2008; Brown et al., 2014; Chang et al., 2010; Collard et al., 2014; de Albuquerque Sousa et al., 2012; Dent and Hoogendijk, 2014; Feng et al., 2014; Fried et al., 2001; Hajek et al., 2016; Jarschik et al., 2012; Jung et al., 2016; Lakey et al., 2012; Lohman et al., 2016, 2014; Makizako et al., 2015; McAdams-DeMarco et al., 2016; Monin et al., 2016; Paulson and Lichtenberg, 2013; Pegorari and Tavares, 2014; Sanchez-Garcia et al., 2014; Woods et al., 2005). Of the 24 included studies, 17 studies provided only cross- sectional data, 3 studies provided only longitudinal data, and 4 studies had both cross-sectional and longitudinal data. One study (Monin 


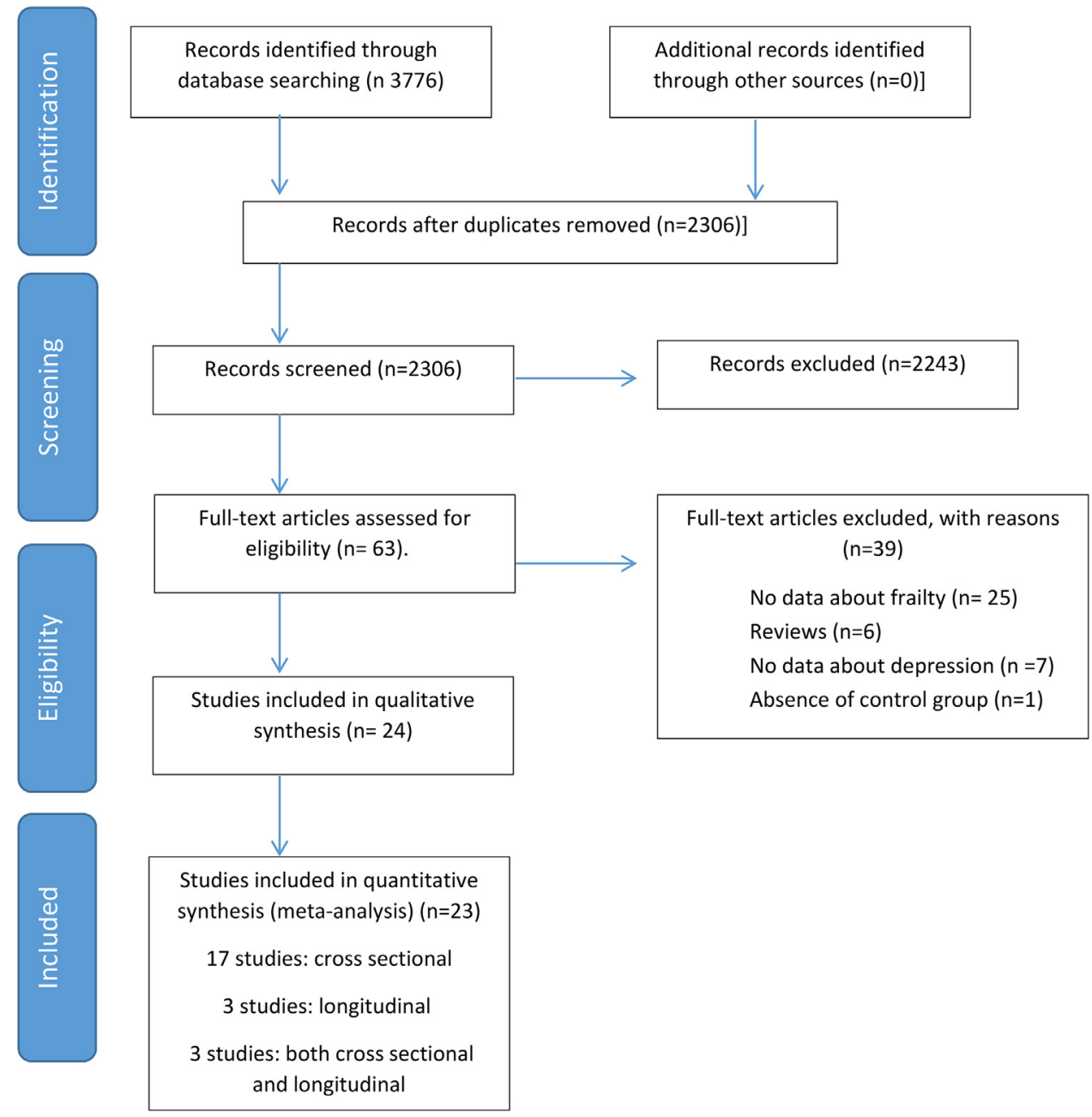

Fig. 1. PRISMA flow-chart.

et al., 2016) did not contain any data that could be included in the meta-analysis.

\subsection{Study and participants' characteristics}

Study and participants' characteristics of cross-sectional studies are summarized in Supplementary Tables 1 and 2. The majority of the studies were conducted among community-dwellers $(n=19(79.1 \%))$ and in North America $(n=12(50.0 \%))$, followed by Europe $(n=4)$, Asia $(n=3)$, Australia $(n=3)$, and Latin America $(n=2)$. (Supplementary Table 1 ). The overall quality of the studies, assessed through NOS, was generally good with a median score $=8$ (range $=5-9$ ) (Full details are available in Supplementary Table 5).

Overall 12 cross-sectional studies (Jarschik et al., 2012; Pegorari and Tavares, 2014; Feng et al., 2014; Matheus et al., 2016; Dent and Hoogendijk, 2014; Chang et al., 2010; Sanchez-Garcia et al., 2014; Patricio de Albuquerque Sousa et al., 2011; Fried et al., 2001; Fugate Woods et al., 2005; Jung et al., 2016; McAdams-DeMarco et al., 2016) investigated the prevalence of depression in frailty including a total of 8023 frail older participants with a mean age of 74.6 years, of whom $94.0 \%$ were female. These participants were compared with 45,775 participants with no frailty (mean age: $70.2 ; 88.1 \%$ females). Furthermore, the 8 cross sectional studies investigating the prevalence of frailty in people with depression (Collard et al., 2014; Lohman et al., 2016; Almeida et al., 2015; Brown et al., 2014; Lohman et al., 2014; Mezuk et al., 2013; Paulson and Lichtenberg, 2013; Almeida et al., 2016) included 2164 depressed older adults with a mean age of 69.3 years, $66.5 \%$ of which were females. These subjects were compared with 14,932 subjects with no depression.

In addition, there were 311 frail older adults in the 3 longitudinal studies (Feng et al., 2014; Makizako et al., 2015; Monin et al., 2016) (mean age $75.1,39.1 \%$ females) investigating the incidence of depression over a mean follow up of 4.67 years. These subjects were compared with 5801 subjects with no frailty at baseline. Finally, there were 6404 depressed older adults in 4 longitudinal studies (Fugate Woods et al., 2005; Paulson and Lichtenberg, 2013; Lakey et al., 2012; Hajek et al., 2016) that investigated the incidence of frailty over a mean follow up of 2.87 years. These participants were compared with 51,610 participants with no depression (Supplementary Tables 3 and 4 ).

\subsection{Measurement of frailty}

Overall, 19 studies used Fried and colleagues' criteria to define frailty ( $\geq 3$ criteria among unintentional weight loss, poor physical activity, slowness, reduced muscular strength, and exhaustion) (Fried et al., 2001). The other measures of frailty include the Women's Health Initiative Observational Study (WHI-OS) ( $\geq 3$ criteria among slowness and exhaustion measured with Rand-36 physical function scale and vital scale and self-reported weight loss $>5 \%$ in the last two years and weekly energy expenditure) $(n=1)$ (Fugate Woods et al., 2005); International Association of Nutrition and Aging (Iana) Task Force definition of frailty $(n=2)$ comprehending five relevant domains: fatigue, resistance, ambulation illnesses 
Table 1

Meta-analysis results of prevalence and odds of depression in older people with frailty.

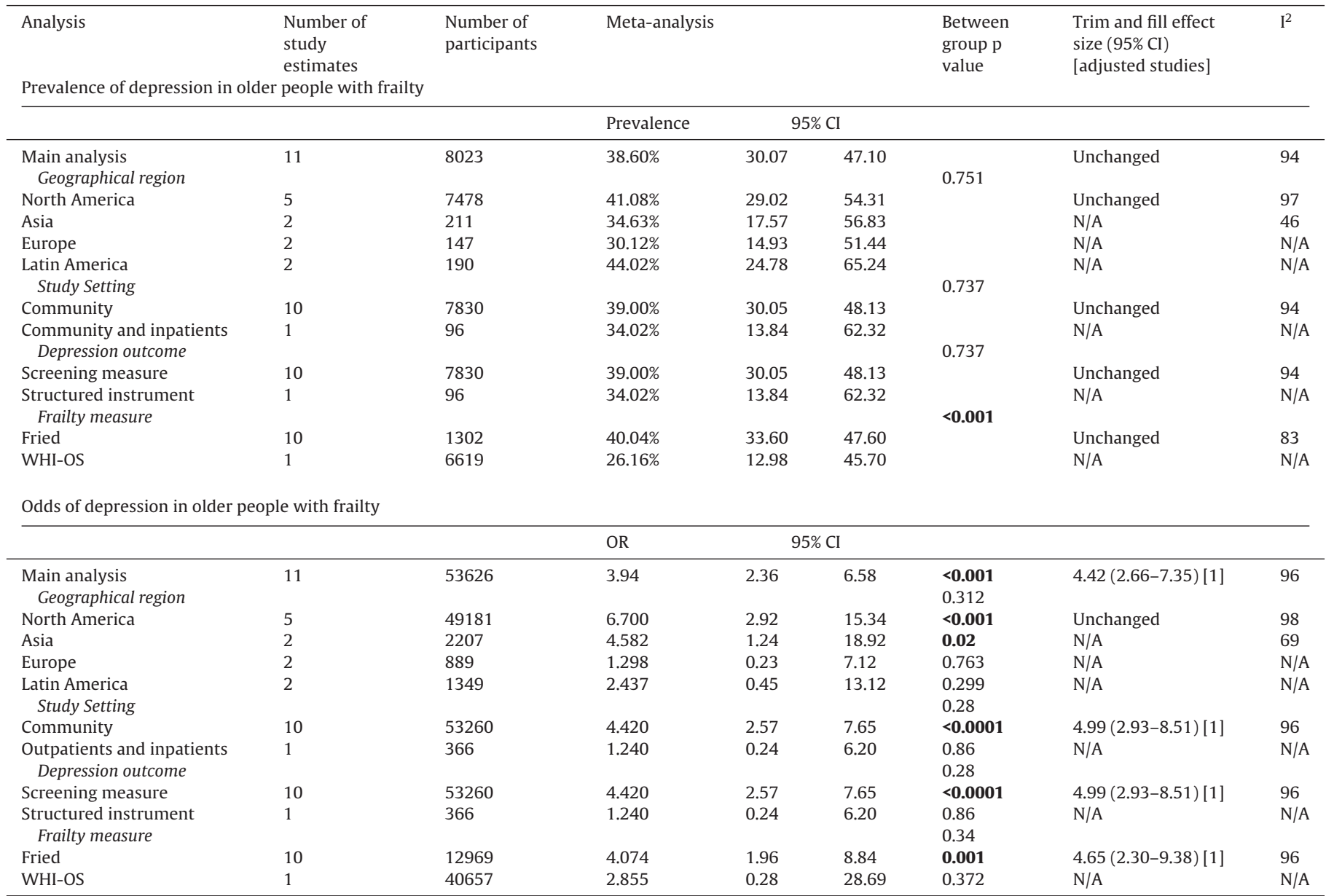

Key: N/A = not applicable, CI: Confidence interval; OR: Odds ratio; WHI-OS: Women's Health Initiative Observational Study.

and loss of weight ( $\geq 3$ criteria) (Abellan van Kan et al., 2008); the adapted frailty index including the following: wasting, weakness, slowness, fatigue or exhaustion, and falls $(n=1)$ (Paulson and Lichtenberg, 2013); and Clinical Frailty Scale ranging from 1 (very fit) to 7 (severely frail) $(n=1)$ (Rockwood et al., 2005).

\subsection{Measurement of depression}

Depressive symptoms were assessed using the CES-D scale $(\mathrm{n}=11)$, the Geriatric Depression Scale (GDS) $(\mathrm{n}=8)$ (Radloff, 1977), and Composite International Diagnostic Interview (CIDI) $(n=2)$ (Wittchen et al., 1991). Three studies adopted different methods including the Patient Health Questionnaire (PHQ-9) (requiring at least 5/9 symptoms) (Kroenke et al., 2001), interview schedule based on the Diagnostic and Statistical Manual of Mental Disorders (DSM III-R) and the Burnam 8-item depression screening instrument (Burnam et al., 1988).

\subsection{Cross-sectional meta-analysis findings}

\subsubsection{Prevalence of depression in people with frailty}

Full details of the prevalence of depression in people with frailty are summarized in Table 1. The overall prevalence of depression in 8023 people with frailty was $38.6 \%$ (95\% CI 30.07-47.10, $\left.\mathrm{I}^{2}=94 \%\right)$. Table 1 shows the prevalence of depression in frail people stratified by geographical region, study setting, depression outcome and definition of frailty. These moderators did not significantly affect our results, although the prevalence of frailty was higher in studies in
Latin America, among community- dwellers, using screening measures for depressive symptoms (instead of structured interviews for MDD) and using the criteria suggested by Fried et al. (Table 1). A visual inspection of funnel plots (available from corresponding author on request) did not suggest publication bias and the trim and fill analyses all remained unchanged when any potential publication bias was adjusted for (Table 1 ).

\subsubsection{Odds of depression in people with frailty versus controls}

Across eleven studies, taking people without frailty as the reference group, frail people had higher odds of having comorbid depression $(\mathrm{OR}=3.95,95 \% \mathrm{CI} 2.36-6.58, \mathrm{p}<0.001)$. After adjusting for publication bias, the OR increased to 4.42 (95\% CI 2.66-7.35). The between group $\mathrm{p}$ values for the subgroup analyses remained non-significant (Table 1 ), however, some results in the subgroups became non-significant which may be due to a small number of studies in some groupings. No study reported the odds of depression in people with frailty, adjusted for potential confounders.

\subsubsection{Prevalence of frailty in people with depression}

Full details of the meta-analysis of the prevalence of frailty in depression are presented in Table 2. In 2167 participants with depression, the prevalence of frailty was $40.40 \%(95 \% \mathrm{CI}$ $27.00-55.30, \mathrm{I}^{2}=97 \%$ ). The prevalence of frailty was significantly higher $(p=0.03)$ in studies capturing depression with a screening measure (49.50\%, 95\% CI 32.50-66.60) compared to a structured clinical diagnosis for MDD (17.62\%, 95\% CI 5.46-44.22) and some variation was noted according to frailty assessment methods, 
Table 2

Meta-analysis results of prevalence and odds of frailty in older people with depression.

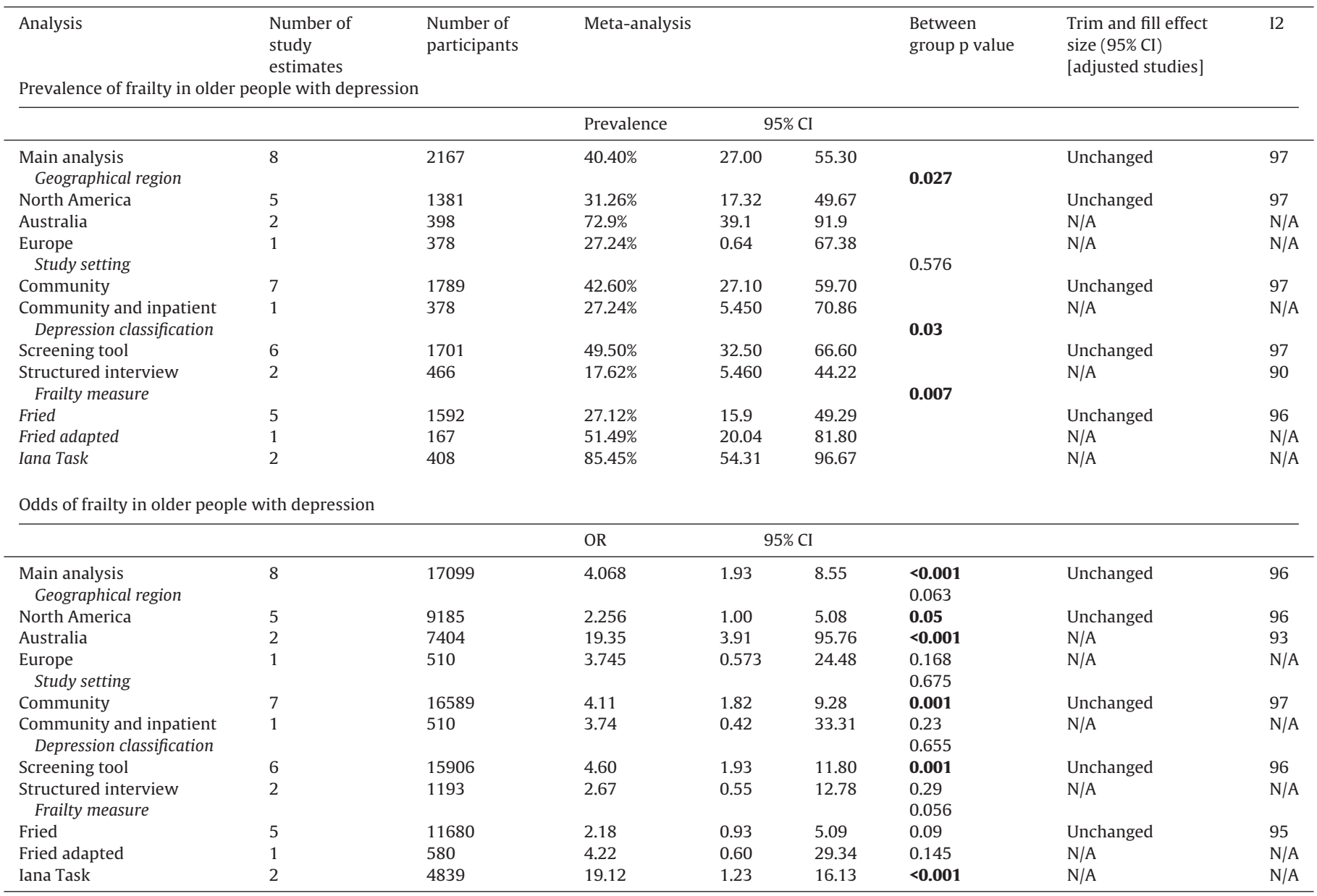

Key: N/A = not applicable, CI: Confidence interval; OR: Odds ratio.

although some caution should be given due to small number of studies in each group (Table 2). The trim and fill analyses all remained unchanged.

\subsubsection{Odds of frailty in people with depression versus controls}

Taking the participants with no depression as reference, people with depression had an increased risk of having frailty $(\mathrm{OR}=4.07$, 95\% CI 1.93-8.55, $\mathrm{p}<0.0001 ; \mathrm{I}^{2}=96 \%$ ) (Table 2). This association was significant in five studies including North Americans ( $\mathrm{OR}=2.25 ; 95 \% \mathrm{CI} 1.00-5.08, \mathrm{p}=0.05 ; \mathrm{I}^{2}=96 \%$ ) compared to other settings (Table 2). As shown in Table 2, publication bias was unlikely.

Four studies (Chang et al., 2010; de Albuquerque Sousa et al., 2012; Jarschik et al., 2012; Pegorari and Tavares, 2014) reported the OR for frailty in adjusted analyses in depressed vs. none depressed people, taking robust participants as reference. After adjusting for a median of 6 potential confounders (range: $3-12$ ), the pooled OR was 2.64 (95\%CI: 1.59-4.37; $\mathrm{I}^{2}=55 \%$; Fig. 2). Another study (Jung et al., 2016 ) reported that an OR of 5.25 (95\%CI: 2.55-10.83) for frailty vs. pre- frailty/robustness, after adjusting for 4 potential confounders.

\subsection{Longitudinal meta-analysis findings}

\subsubsection{Studies investigating incident frailty in older people with depression}

Overall, 6404 older adults with depression at baseline were followed over a mean of 2.87 years investigating incident frailty (Fugate Woods et al., 2005; Paulson and Lichtenberg, 2013; Lakey et al., 2012; Hajek et al., 2016). The pooled OR for incident frailty, adjusted for a median of 7 potential confounders (range: $0-21$ ) (Supplementary Table 3), was 3.72 (95\%CI 1.95-7.08; $\mathrm{p}<0.0001$; $\left.I^{2}=98 \%\right)$, as shown in Fig. 3 .

\subsubsection{Studies investigating incident depression among people with frailty}

Overall, two longitudinal studies (Feng et al., 2014; Makizako et al., 2015) including 4852 older adults investigated incident depression as the outcome. These two studies found that frailty at the baseline increased the risk of incident depression by about $90 \%$ ( $\mathrm{OR}=1.90 ; 95 \% \mathrm{CI} 1.55-2.32, \mathrm{p}<0.0001 ; \mathrm{I}^{2}=0 \%$ ), after adjusting for 11 covariates (Fig. 4; Supplementary Table 4). One study (Monin et al., 2016) with no meta-analyzable data reported an association between depression and frailty in 1260 community-dwelling married couples.

\section{Discussion}

In this meta-analysis, for the first time, we have considered the possible bidirectional relationship between frailty and depression summarizing the data of both cross-sectional and longitudinal studies. In summary, our data suggests that across cross-sectional studies, approximately forty percent of individuals with depression have frailty and a similar proportion of those with frailty have depression. Our comparative meta- analysis suggests that frail older people are four times more likely to have depression than non-frail people. A similar increased odds for frailty was evident 


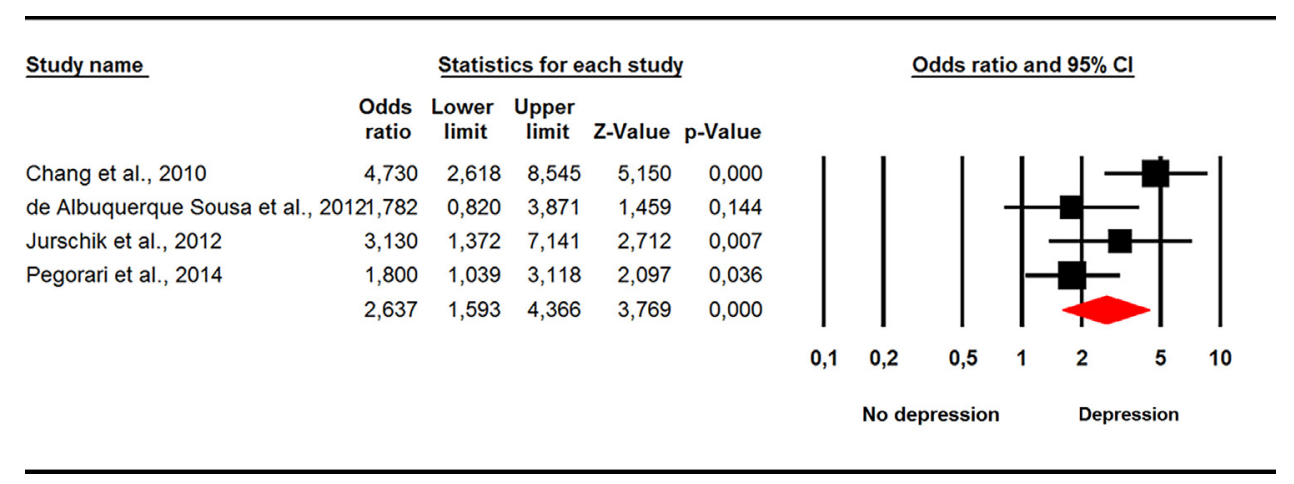

Fig. 2. Odds of frailty in people with depression versus controls.

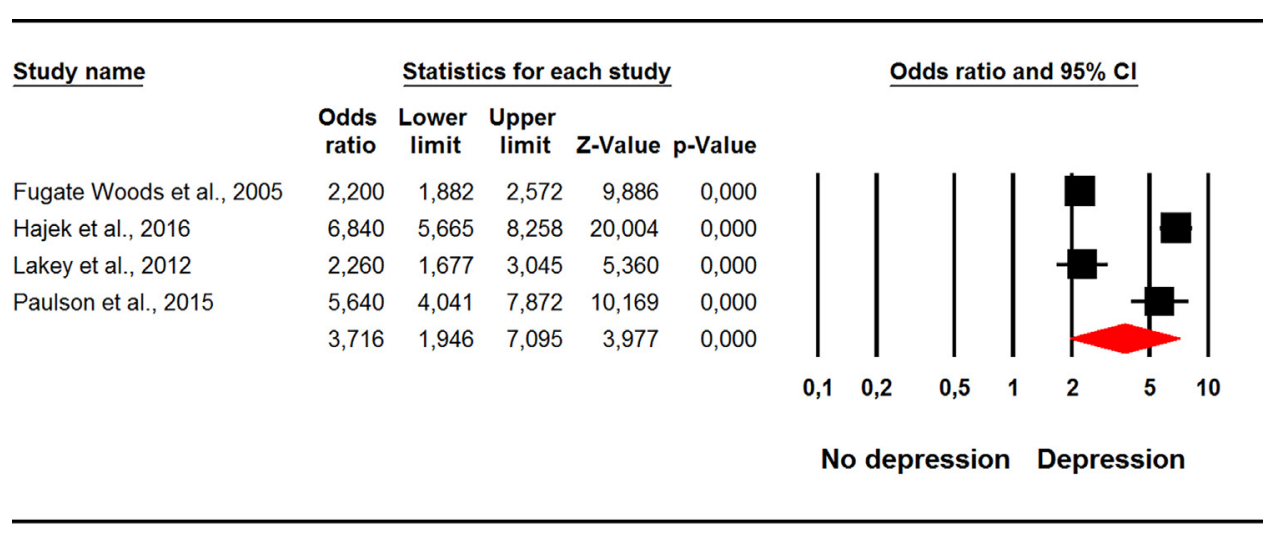

Meta Analysis

Fig. 3. Odds for incident frailty in older people with depression.

\begin{tabular}{|c|c|c|c|c|c|c|c|c|c|c|c|}
\hline \multirow[t]{2}{*}{ Study name } & \multicolumn{5}{|c|}{ Statistics for each study } & \multicolumn{6}{|c|}{ Odds ratio and $95 \% \mathrm{Cl}$} \\
\hline & $\begin{array}{c}\text { Odds } \\
\text { ratio }\end{array}$ & $\begin{array}{c}\text { Lower } \\
\text { limit }\end{array}$ & $\begin{array}{c}\text { Upper } \\
\text { limit }\end{array}$ & Z-Value & p-Value & & & & & & \\
\hline Feng et al., 2014 & 3,090 & 1,122 & 8,513 & 2,182 & 0,029 & & & & & 1 & - \\
\hline \multirow[t]{4}{*}{ Makizako et al., 2015} & 1,860 & 1,517 & 2,280 & 5,974 & 0,000 & & & & & & \\
\hline & 1,897 & 1,554 & 2,316 & 6,287 & 0,000 & & & & & & \\
\hline & & & & & & 0,1 & 0,2 & 0,5 & 1 & 2 & 10 \\
\hline & & & & & & & No $f$ & ailty & & Frailty & \\
\hline
\end{tabular}

Meta Analysis

Fig. 4. Odds for incident depression among people with frailty.

in older people with depression versus those without depression. Longitudinal studies substantially confirmed these findings despite being more limited in number.

Frailty, is a multifactorial geriatric syndrome, which could be influenced by pain, mobility and balance problems, weakness, poor endurance etc. All of these risk factors may lead to disability, or functional dependence, and thus lead to depression (Fugate Woods et al., 2005). On the other hand, depression may also predict indicators of frailty due to the decrease in social ties, gait speed, and less physical activities, or due to the increase in sedentary life, fall risk, weight loss, and malnutrition, which may increase the perpetuation of affective symptoms typical of depression including sadness, anhedonia, and helplessness (Hajek et al., 2016; Paulson and Lichtenberg, 2013). Additionally, depression may not only be associated with physical frailty, but also with cognitive impairment, which may be long-lasting and may persist even during affective remission (Bortolato et al., 2016). Depression-related cognitive impairment may contribute to the emergence of frailty. It is also possible that there are shared risk factors and pathophysiological pathways. First, these reciprocal associations may be at least partly explained by overlapping mechanisms such as cerebrovascular disease, chronic inflammation, oxidative stress, mitochondrial dysfunction (Brown et al., 2016), hypothalamicpituitary-adrenal (HPA) axis dysregulation (Belvederi et al., 2014), among others (Katz, 2004; Soysal et al., 2016, 2017). Subclinical vascular diseases that cause pre-frontal white-matter hyperintensities in patients with late-life depression have consistently been considered a key factor in prefrailty (Newberg et al., 2006). Grow- 
ing evidence also supports a positive association between frailty and the inflammatory cytokines, such as interleukin 6 (IL 6) (Soysal et al., 2016), which is also known to be elevated in individuals with late life depression (Vaughan et al., 2015). Inflammatory cytokines are associated with both decreased muscle mass and strength, and also negatively affect the central dopaminergic function, which may result in depressive affect, fatigue, and cognitive and motor slowing (Brown et al., 2016). Mitochondrial dysfunction has also been identified in numerous neurodegenerative diseases as well as depression. Muscle biopsies in patients with depression have shown decreased ATP production, and adults with depression had also impaired mitochondrial respiration in peripheral blood mononuclear cells, most strongly correlating with the symptom of fatigue (Brown et al., 2016). The detrimental cycle between declined activity, mobility, and energy levels resembles the clinical presentation of depression as well as those with the frailty syndrome (Brown et al., 2016). Another hypothesis is that HPA axis dysregulation, as well as aberrations in other mediators, such as insulin-like growth factor, and testosterone (Belvederi et al., 2014), have been reported in frail persons with significant depressive symptoms and may account for the reciprocal association herein observed (von Zerssen et al., 1986). Moreover, the beneficial effects of the approaches to prevent frailty or depression may protect the other. For example, the successful treatment of the depression itself may result in increased behavioral and social activation, thereby increasing physical and social activity levels, improving muscle mass and strength, and the elder's overall energy levels, thereby, reducing frailty (Lakey et al., 2012). Similarly, increasing physical activity is an effective intervention for frailty in older adults, and can protect and manage depressive symptoms in the elderly through potential neurobiological changes and as a consequence of social and physical engagement (Brown et al., 2016; Schuch et al., 2016a,b). Other interventions such as improving balance and muscle strength, and vitamin D supplementation may also play a role in preventing or treating frailty (Brouwer-Brolsma et al., 2013). Depressive symptoms may cause vitamin D deficiency via decreased sun exposure, poorer dietary intake and more smoking (Brouwer-Brolsma et al., 2013). In fact, all these findings support the bidirectionality of the depression-frailty relationship. Clearly, future research is required to explore and understand such relationships.

Our comprehensive meta-analysis results advance the literature from previously published narrative and/or selective reviews that have considered the relationship between depression and frailty. Meta-analyses enable the logical pooling of data and enable a more precise estimate of the prevalence and/or odds of an outcome than when making subjective considerations of individual studies separately such as those in previous narrative reviews (Ioannidis and Lau, 1999). Nonetheless, the previous reviews have illustrated some interesting findings. One review, including 28 studies, reported that frailty and depression are comorbid geriatric syndromes in a subgroup of older individuals, and that frailty is also a risk factor for the development and persistence of depressive symptoms (Buigues et al., 2015). Another review, including both cross-sectional $(n=16)$ and cohort studies $(n=23)$ indicated that frailty, its components, and functional impairment are risk factors for depression (Mezuk et al., 2012). On the other hand, another review found that the relationship between depressive symptomatology and increased risk of incident frailty was robust, while the opposite relationship was less conclusive (Vaughan et al., 2015). However, the potential role of antidepressant medications on frailty has not been clearly evaluated in any of these reviews. Because, as shown in the review by Benraad et al, geriatric characteristics are rarely taken into account in trials on antidepressant drugs in late-life depression (Benraad et al., 2016). To differentiate from these previous reviews, the metaanalysis was performed in the present study (Buigues et al., 2015;
Mezuk et al., 2012). Specifically our data established that frail older people are four times more likely to have depression compared to controls, with similar increased odds for frailty among those with depression versus controls. While cross-sectional studies are unable to clarify the directionality of the relationship between frailty and depression, it clearly indicates that there is a high level of comorbidity. Whether or not this is attributed to mutually exclusive or overlapping symptomology of each condition is not clear and future prospective research may help to disentangle this relationship and explore potential overlapping symptomology and disease onset. Nonetheless, the limited number prospective studies does suggest that after adjusting for confounders, people with depression are at increased risk of developing frailty, whilst the converse relationship also appears to be evident. However, the small number of longitudinal studies precludes any definitive conclusions and future longitudinal research is required to specifically attempt to differentiate between the signs and symptoms of both conditions.

Some factors were identified in our analyses as being potentially important in explaining the association between depression and frailty. The prevalence of depression in frail people, in fact, was higher in studies from Latin America, among community-dwellers, those using depression screening measures (instead structured interviews) and in studies which considered criteria suggested by Fried et al. (2001) A recent international study demonstrated that depressive symptoms are more pronounced within traditional family based value patterns, like Latin America, possibly because of higher expectations of the availability of family support that are often only partially fulfilled due to recent changes in family structure (Ylli et al., 2016). Fried's criteria shares symptoms with the CES-D and this could partially explain the high correlation. However, some studies have found that the strong association between frailty and depression is not unique to a single definition of frailty such as the Clinical Frailty Index, and thus, our findings do not seem to be fully explained by shared symptomatology (Lohman et al., 2014). We also examined the opposite relationship, i.e. the prevalence of depression among the frail and the odds and incidence of depression in frail older individuals compared to robust ones. Depressed people showed significantly higher levels of frailty ( $\sim 40 \%)$, mainly in North American studies and in one Australian study (Almeida et al., 2015).

Prospective studies of the relationship between depression and incident frailty also suggest that depression may increase the risk of frailty (Vaughan et al., 2015). Depression is associated with increased weakness, mobility deficits, and fatigue, which may thus increase the risk of frailty and increased mortality over a period of up to 5 years (Veronese et al., 2016). The role of antidepressant drug treatment in the relationship between depression and frailty deserve further investigation. Antidepressants have been associated with a higher risk of incident frailty (Lakey et al., 2012). This association could simply be explained by a more severe and chronic form of depression that required the use of antidepressant drugs (Vaughan et al., 2015), but a large prospective observational study reported that even in the absence of depressive symptoms, antidepressant use was associated with becoming frail (Lakey et al., 2012). Therefore, non- pharmacological interventions may be an important approach for depressed frail older adults. Clearly further research is needed to elucidate the possible role of drugs in the depression-frailty relationship (Mezuk et al., 2012).

\section{Limitations}

Whilst our data provides some novel insights, some limitations should be acknowledged. The most important lies in that the evidence is largely drawn from case-control and crosssectional studies. Thus the directionality and degree of overlap 
between these two constructs is not clear. In addition, the number of prospective studies was limited, therefore future prospective research is required to allow a better elucidation of potential moderators which could influence the reciprocal prospective associations between depression and frailty. A second limitation is the high heterogeneity observed. The different methods and different cut-off values used for defining frailty and depression might play a role, but our findings suggest that these factors cannot completely explain the observed reciprocal associations. Third, there was limited information on important moderators such as physical activity, medication use, presence of dementia, and inflammatory cytokines. Fourth, depression was diagnosed through non-original methods (DSM), and only four studies (Anand et al., 2012; Feng et al., 2014; Fried et al., 2001; Lakey et al., 2012) reported data regarding antidepressants, thus precluding the possibility to conduct a meta-analysis. However, in one large longitudinal study, the use of antidepressants was associated with a higher incidence of frailty indicating that this factor is of importance in the association between depression and frailty (Lakey et al., 2012). Thus, future research should consider the relationship between antidepressant medication and frailty/depression. Finally, the presence of depressive symptoms in the construct of frailty may artificially contribute to the relationship between frailty and depression. More research is required to investigate the relationship between major depression and clearly defined frailty in particular. Such research might also consider the relationship of important potential moderators such as physical activity, antidepressant medication and inflammatory markers.

In conclusion, our results provide evidence for a consistent bidirectional relationship between frailty and depression among older people. However, the precise mechanisms underpinning those reciprocal epidemiological associations deserve further investigation. Our data suggest that over a third of people with frailty have depression and a similar proportion of people with depression have frailty, while the odds of each condition are four times higher than controls. Therefore, interventions designed to decrease one of both syndromes can prevent the emergence of other. Our data is of public health importance and may open important perspectives for the prevention and treatment of those highly co-occurring and prevalent conditions.

\section{Conflict of interest}

None.

\section{Financial disclosure}

Soysal, Veronese, Thompson, Kahl, Fernandes, Prina, Solmi, Schofield, Koyanagi, Tseng, Lin,Chu, Cosco, Cesari, Carvalho, Stubbs have nothing to disclose.

Ai Koyanagi's work is supported by the Miguel Servet contract financed by the CP13/00150 and PI15/00862 projects, integrated into the National R+D + I and funded by the ISCIII - General Branch Evaluation and Promotion of Health Research - and the European Regional Development Fund (ERDF-FEDER). TDC is supported by a Canadian Institutes of Health Research Postdoctoral Fellowship (MFE-146676).

Brendon Stubbs is supported by the National Institute for Health Research (NIHR) Collaboration for Leadership in Applied Health Research and Care South London at King's College Hospital NHS Foundation Trust. The views expressed are those of the author(s) and not necessarily those of the NHS, the NIHR or the Department of Health

\section{Appendix A. Supplementary data}

Supplementary data associated with this article can be found, in the online version, at http://dx.doi.org/10.1016/j.arr.2017.03.005.

\section{References}

Abellan van Kan, G., Rolland, Y., Bergman, H., et al., 2008. The I.A.N.A Task Force on frailty assessment of older people in clinical practice. J. Nutr. Health Aging 12, $29 \mathrm{e} 37$.

Almeida, O.P., Hankey, G.J., Yeap, B.B., Golledge, J., Norman, P.E., Flicker, L., 2015. Depression, frailty, and all-cause mortality: a cohort study of men older than 75 years. J. Am. Med. Dir. Assoc. 16, 296-300, http://dx.doi.org/10.1016/j. jamda.2014.10.023.

Almeida, O.P., McCaul, K., Hankey, G.J., Yeap, B.B., Golledge, J., Norman, P.E., Flicker, L., 2016. Duration of diabetes and its association with depression in later life: the Health in Men Study (HIMS). Maturitas 86, 3-9, http://dx.doi.org/10.1016/ j.maturitas.2016.01.003.

Anand, A., Gunn, A.D., Barkay, G., Karne, H.S., Nurnberger, J.I., Mathew, S.J., Ghosh, S., 2012. Early antidepressant effect of memantine during augmentation of lamotrigine inadequate response in bipolar depression: a double-blind, randomized, placebo-controlled trial. Bipolar Disord. 14, 64-70, http://dx.doi. $\operatorname{org} / 10.1111 /$ j.1399- 5618.2011.00971.x.

Badalà, F., Nouri-mahdavi, K., Raoof, D.A., 2008. NIH public access. Computer (Long Beach. Calif.) 144, 724-732, http://dx.doi.org/10.1038/jid.2014.371.

Benraad, C.E.M., Kamerman-Celie, F., van Munster, B.C., Oude Voshaar, R.C., Spijker, J., Olde Rikkert, M.G.M., 2016. Geriatric characteristics in randomised controlled trials on antidepressant drugs for older adults: a systematic review. Int. J. Geriatr. Psychiatry 31, 990-1003, http://dx.doi.org/10.1002/gps.4443.

Belvederi, M. Murri, Pariante, C., Mondelli, V., Masotti, M., Atti, A.R., Mellacqua, Z., Antonioli, M., Ghio, L., Menchetti, M., Zanetidou, S., Innamorati, M., Amore, M., 2014. HPA axis and aging in depression: systematic review and meta-analysis. Psychoneuroendocrinology 41, 46-62, http://dx.doi.org/10.1016/j.psyneuen. 2013.12.004.

Bortolato, B., Miskowiak, K.W., Köhler, C.A., Maes, M., Fernandes, B.S., Berk, M., Carvalho, A.F., 2016. Cognitive remission: a novel objective for the treatment of major depression? BMC Med. 22 (14:9), http://dx.doi.org/10.1186/s12916016-0560-3.

Brouwer-Brolsma, E.M. van de Rest, O., Tieland, M., van der Zwaluw, N.L, Steegenga, W.T., Adam, J.J., van Loon, L.J., Feskens, E.J., de Groot, L.C., 2013. Serum 25-hydroxyvitamin D is associated with cognitive executive function in Dutch prefrail and frail elderly: a cross-sectional study exploring the associations of 25-hydroxyvitamin D with glucose metabolism, cognitive performance and depression. J. Am. Med. Dir. Assoc. 06, 010.

Brown, P.J., Roose, S.P., Fieo, R., Liu, X., Rantanen, T., Sneed, J.R., Rutherford, B.R., Devanand, D.P., Avlund, K., 2014. Frailty and depression in older adults: a high-risk clinical population. Am. J. Geriatr. Psychiatry 22, 1083-1095, http:// dx.doi.org/10.1016/j.jagp.2013.04.010.

Brown, P.J., Rutherford, B.R., Yaffe, K., Tandler, J.M., Ray, J.L., Pott, E., Chung, S., Roose, S.P., 2016. The depressed frail phenotype: The clinical manifestation of increased biological aging. Am. J. Geriatr. Psychiatry. 24 (11), 1084-1094, http://dx.doi.org/10.1016/j.jagp.2016.06.005.

Buigues, C., Padilla-Sánchez, C., Garrido, J.F., Navarro-Martínez, R., Ruiz-Ros, V. Cauli, O., 2015. The relationship between depression and frailty syndrome: a systematic review. Aging Ment. Health 19, 762-772, http://dx.doi.org/10.1080/ 13607863.2014.967174.

Burnam, M.A., Wells, K.B., Leake, B., Landsverk, J., 1988. Development of a brief screening instrument for detecting depressive disorders. Med Care 26 (8), $775-789$.

Chang, S.S., Weiss, C.O., Xue, Q.L., Fried, L.P., 2010. Patterns of comorbid inflammatory diseases in frail older women: the women's health and aging studies I and II. J. Gerontol. Ser. A- Biol. Sci. Med. Sci. 65, 407-413, http://dx. doi.org/10.1093/gerona/glp181.

Clegg, A., Young, J., Iliffe, S., Rikkert, M.O., Rockwood, K., 2013. Frailty in elderly people. Lancet 381, 752-762, http://dx.doi.org/10.1016/S01406736(12) 62167-9.

Collard, R.M., Boter, H., Schoevers, R.A., Oude Voshaar, R.C., 2012. Prevalence of frailty in community-dwelling older persons: a systematic review. J. Am. Geriatr. Soc. 60, 1487-1492, http://dx.doi.org/10.1111/j.1532-5415.2012 04054.x.

Collard, R.M., Comijs, H.C., Naarding, P., Oude Voshaar, R.C., 2014. Physical frailty: vulnerability of patients suffering from late-life depression. Aging Ment. Health 18, 570-578, http://dx.doi.org/10.1080/13607863.2013.827628.

de Albuquerque Sousa, Patrício, Dias, R.C., Maciel álvaro, C.C., Guerra, R.O., 2012 Frailty syndrome and associated factors in community-dwelling elderly in Northeast Brazil. Arch. Gerontol. Geriatr., 54, http://dx.doi.org/10.1016/j. archger.2011.08.010.

Dent, E., Hoogendijk, E.O., 2014. Psychosocial factors modify the association of frailty with adverse outcomes: a prospective study of hospitalised older people. BMC Geriatr. 14, 108, http://dx.doi.org/10.1186/1471-2318-14-108.

Drey, M., Pfeifer, K., Sieber, C.C., Bauer, J.M., 2011. The Fried frailty criteria as inclusion criteria for a randomized controlled trial: personal experience and literature review. Gerontology 57 (1), 11-18, http://dx.doi.org/10.1159/ 000313433. 
Duval, S., Tweedie, R., 2000. Trim and fill: a simple funnel-plot-based method of testing and adjusting for publication bias in meta-analysis. Biometrics 56, 455-463, http://dx.doi.org/10.1111/j.0006- 341x.2000.00455.x.

Feng, L., Nyunt, M.S.Z., Feng, L., Yap, K.B., Ng, T.P., 2014. Frailty predicts new and persistent depressive symptoms among community-dwelling older adults: findings from singapore longitudinal aging study. J. Am. Med. Dir. Assoc. 15 http://dx.doi.org/10.1016/j.jamda.2013.10.001.

Fried, L.P., Tangen, C.M., Walston, J., Newman, A.B., Hirsch, C., Gottdiener, J., Seeman, T., Tracy, R., Kop, W.J., Burke, G., McBurnie, M.A., 2001. Frailty in older adults: evidence for a phenotype. J. Gerontol. A Biol. Sci. Med. Sci. 56, M146-M156.

Fugate Woods, N., LaCroix, A.Z., Gray, S.L., Aragaki, A., Cochrane, B.B., Brunner, R.L., Masaki, K., Murray, A., Newman, A.B., 2005. Frailty: emergence and consequences in women aged 65 and older in the women's health initiative observational study. J. Am. Geriatr. Soc. 53, 1321-1330, http://dx.doi.org/10. $1111 / \mathrm{j} .1532-5415.2005 .53405 . x$.

Hajek, A., Brettschneider, C., Posselt, T., Lange, C., Mamone, S., Wiese, B., Weyerer, S., Werle, J., Fuchs, A., Pentzek, M., Stein, J., Luck, T., Bickel, H., Mosch, E., Heser, K., Jessen, F., Maier, W., Scherer, M., Riedel-Heller, S.G., Konig, H.-H., 2016. Predictors of frailty in old age - results of a longitudinal study. J. Nutr. Health Aging 20, 952-957, http://dx.doi.org/10.1007/s12603-015-0634-5.

Hare, D.L., Toukhsati, S.R., Johansson, P., Jaarsma, T., 2014. Depression and cardiovascular disease: a clinical review. Eur. Heart J. 35, 1365-1372, http://dx doi.org/10.1093/eurheartj/eht462.

Higgins, J.P.T., Thompson, S.G., 2002. Quantifying heterogeneity in a meta-analysis. Stat. Med. 21, 1539-1558, http://dx.doi.org/10.1002/sim.1186.

Ioannidis, J.P., Lau, J., 1999. Pooling research results: benefits and limitations of meta- analysis. Jt. Comm. J. Qual. Improv. 25 (9), 462-469.

Jarschik, P., Nunin, C., Botigu, T., Escobar, M.A., Lavedan, A., Viladrosa, M., 2012. Prevalence of frailty and factors associated with frailty in the elderly population of Lleida Spain: the FRALLE survey. Arch. Gerontol. Geriatr. 55, 625-631, http://dx.doi.org/10.1016/j.archger.2012.07.002.

Jung, H., Jang, I., Lee, Y.S., Lee, C.K., Cho, E., Kang, W.Y., Kim, D.H., 2016. Prevalence of frailty and aging-related health conditions in older koreans in rural communities: a cross-sectional analysis of the aging study of pyeongchang rural area. J. Korean Med. Sci., 345-352, http://dx.doi.org/10.3346/jkms.2016. 31.3.345.

Katz, I.R., 2004. Depression and frailty: the need for multidisciplinary research. Am. J. Geriatr. Psychiatry 12, 1-6.

Kroenke, K., Spitzer, R.L., Williams, J.B., 2001. The PHQ-9: validity of a brief depression severity measure. J. Gen. Intern. Med. 16 (9), 606-613.

Lakey, S.L., Lacroix, A.Z., Gray, S.L., Borson, S., Williams, C.D., Calhoun, D., Goveas, J.S., Smoller, J.W., Ockene, J.K., Masaki, K.H., Coday, M.E., Rosal, M.C., Woods, N.F., 2012. Antidepressant use, depressive symptoms, and incident frailty in women aged 65 and older from the Women'S Health Initiative Observational Study. J. Am. Geriatr. Soc. 60, 854-861, http://dx.doi.org/10.1111/j.1532-5415. 2012.03940.x.

Liberati, A., Altman, D.G., Tetzlaff, J., Mulrow, C., Gøtzsche, P.C., Ioannidis, J.P.A., Clarke, M., Devereaux, P.J., Kleijnen, J., Moher, D., 2009. The PRISMA statement for reporting systematic reviews and meta-analyses of studies that evaluate health care interventions: explanation and elaboration. PLoS Med. 6, http://dx doi.org/10.1371/journal.pmed.1000100 (e1000100).

Lohman, M., Dumenci, L., Mezuk, B., 2014. Sex differences in the construct overlap of frailty and depression: evidence from the health and retirement study. J. Am. Geriatr. Soc. 62, 500-505, http://dx.doi.org/10.1111/jgs.12689.

Lohman, M., Dumenci, L., Mezuk, B., 2016. Depression and frailty in late life: evidence for a common vulnerability. J. Gerontol. -Ser. B Psychol. Sci. Soc. Sci. 71, 630-640, http://dx.doi.org/10.1093/geronb/gbu180.

Lohman, L., 2013. Construct overlap between depression and frailty in later life: evidence from the health and retirement study. Compr. Psychiatry, http://dx. doi.org/10.1016/j.comppsych.2012.07.032.

Matheus Arts, H.L., Collard, R.M., Comijs, H.C., Zuidersma, M., de Rooij, S.E. Naarding, P., Oude Voshaar, R.C., 2016. Physical frailty and cognitive functioning in depressed older adults: findings from the NESDO study. J. Am. Med. Dir. Assoc. 17, 36-43, http://dx.doi.org/10.1016/j.jamda.2015.07.016.

Makizako, H., Shimada, H., Doi, T., Yoshida, D., Anan, Y., Tsutsumimoto, K., Uemura K., Liu- Ambrose, T., Park, H., Lee, S., Suzuki, T., 2015. Physical frailty predicts incident depressive symptoms in elderly people: prospective findings from the Obu Study of Health Promotion for the Elderly. J. Am. Med. Dir. Assoc. 16, 194-199, http://dx.doi.org/10.1016/j.jamda.2014.08.017.

McAdams-DeMarco, M.A., Ying, H., Olorundare, I., King, E.A., Haugen, C., Buta, B. Gross, A.L., Kalyani, R., Desai, N.M., Dagher, N.N., Lonze, B.E., Montgomery, R.A., Bandeen-Roche, K., Walston, J.D., Segev, D.L., 2016. Individual frailty components and mortality In kidney transplant recipients. Transplantation, 1 http://dx.doi.org/10.1097/tp.0000000000001546.

Mezuk, B., Edwards, L., Lohman, M., Choi, M., Lapane, K., 2012. Depression and frailty in later life: a synthetic review. Int. J. Geriatr. Psychiatry 27, 879-892, http://dx.doi.org/10.1002/gps.2807.

Mezuk, B., Lohman, M., Dumenci, L., Lapane, K.L., 2013. Are depression and frailty overlapping syndromes in mid- and late-life? A latent variable analysis. Am. J. Geriatr. Psychiatry 21, 560-569, http://dx.doi.org/10.1016/j.jagp.2012.12.019.
Monin, J., Doyle, M., Levy, B., Schulz, R., Fried, T., Kershaw, T., 2016. Spousal associations between frailty and depressive symptoms: longitudinal findings from the cardiovascular health study. J. Am. Geriatr. Soc. 64, 824-830, http:// dx.doi.org/10.1111/jgs.14023.

Newberg, A.R., Davydow, D.S., Lee, H.B., 2006. Cerebrovascular disease basis of depression: post-stroke depression and vascular depression. Int. Rev. Psychiatry 18, 433-441, http://dx.doi.org/10.1080/09540260600935447.

Paulson, D., Lichtenberg, P.A., 2013. Vascular depression: an early warning sign of frailty. Aging Ment. Health 17, 85-93, http://dx.doi.org/10.1080/13607863. 2012.692767.

Pegorari, M.S., Tavares, D.M.D.S., 2014. Factors associated with the frailty syndrome in elderly individuals living in the urban area. Rev. Lat. Am. Enfermagem 22, 874-882, http://dx.doi.org/10.1590/0104- 1169.0213.2493.

Potter, G.G., McQuoid, D.R., Whitson, H.E., Steffens, D.C., 2016. Physical frailty in late-life depression is associated with deficits in speed-dependent executive functions. Int. J. Geriatr. Psychiatry 31, 466-474, http://dx.doi.org/10.1002/gps 4351.

Radloff, L.S., 1977. The CES-D scale: a self-report depression scale for research in the general population. Appl. Psychol. Meas. 1, 385-401, http://dx.doi.org/10 $1177 / 014662167700100306$.

Rockwood, K., Song, X., MacKnight, C., Bergman, H., Hogan, D.B., McDowell, I. Mitnitski, A., 2005. A global clinical measure of fitness and frailty in elderly people. CMAJ 173 (5), 489-495.

Rodda, J., Walker, Z., Carter, J., 2011. Depression in older adults. BMJ 343, http://dx. doi.org/10.1136/bmj.d5219.

Sanchez-Garcia, S., Sanchez-Arenas, R., Garcia-Pereira, C., Rosas-Carrasco, O., Avila-Funes, J.A., Ruiz-Arregui, L., Juarez-Cedillo, T., 2014. Frailty among community-dwelling elderly Mexican people: prevalence and association with sociodemographic characteristics, health state and the use of health services. Geriatr. Gerontol. Int. 14, 395-402, http://dx.doi.org/10.1111/ggi.12114.

Schuch, F.B., Deslandes, A.C., Stubbs, B., Gosmann, N.P., Silva, C.T., Fleck, M.P., 2016a. Neurobiological effects of exercise on major depressive disorder: a systematic review. Neurosci. Biobehav. Rev. 61, 1-11, http://dx.doi.org/10. 1016/j.neubiorev.2015.11.012.

Schuch, F.B., Vancampfort, D., Rosenbaum, S., Richards, J., Ward, P.B., Veronese, N., Solmi, M., Cadore, E.L., Stubbs, B., 2016b. Exercise for depression in older adults: a meta-analysis of randomized controlled trials adjusting for publication bias. Rev. Bras. Psiquiatr. 38 (3), 247-254, http://dx.doi.org/10. 1590/1516-4446-2016- 1915.

Soysal, P., Stubbs, B., Lucato, P., Luchini, C., Solmi, M., Peluso, R., Sergi, G., Isik, A.T., Manzato, E., Maggi, S., Maggio, M., Prina, A.M., Cosco, T.D., Wu, Y.-T., Veronese, N., 2016. Inflammation and frailty in the elderly: a systematic review and meta-analysis. Ageing Res. Rev. 31, 1-8, http://dx.doi.org/10.1016/j.arr.2016. 08.006 .

Soysal Pinar, Isik Ahmet Turan, Carvalho Andre F., Fernandes Brisa S., Solmi Marco, Schofield Patricia, Veronese Nicola, Stubbs Brendon, 2017. Oxidative stress and frailty: A systematic review and synthesis of the best evidence. http://dx.doi.org/10.1016/j.maturitas.2017.01.006 (in press).

von Elm, E., Altman, D.G., Egger, M., Pocock, S.J., Gøtzsche, P.C., Vandenbroucke, J.P., for the STROBE Initiative, 2008. The Strengthening the Reporting of Observational Studies in Epidemiology (STROBE) statement: guildelines for reporting observational studies. J. Clin. Epidemiol. 61, 344-349, http://dx.doi. org/10.1016/j.jclinepi.2007.11.008.

von Zerssen, D., Berger, M., Dose, M., Doerr, P., Krieg, C., Bossert, S., Riemann, D., Pirke, K.M., Dolhofer, R., Müller, O.A., 1986. The nature of neuroendocrine abnormalities in depression: a controversial issue in contemporary psychiatry. Psychiatr. Dev. 4, 237-256.

Vaughan, L., Corbin, A.L., Goveas, J.S., 2015. Depression and frailty in later life: a systematic review. Clin. Interv. Aging 10, 1947-1958, http://dx.doi.org/10. 2147/CIA.S69632.

Veronese, N., Stubbs, B., Fontana, L., Trevisan, C., Bolzetta, F., Rui, M., Sartori, De, Musacchio, L., Zambon, E., Maggi, S., Perissinotto, S., Corti, E., Crepaldi, M.C., Manzato, G., Sergi, E., 2016. A comparison of objective physical performance tests and future mortality in the elderly people. J. Gerontol. A. Biol. Sci. Med. Sci. (July 28), http://dx.doi.org/10.1093/gerona/glw139, pii: glw139.

Wells, G., Shea, B., O'Connell, D., Peterson, J., Welch, V., Losos, M., Tugwell, P., 2012. The Newcastle- Ottawa Scale (NOS) for Assessing the Quality If Nonrandomized Studies in Meta- Analyses., http://dx.doi.org/10.2307/632432 (Available from URL: http//www.ohrid.ca/programs/clinicalepidemiology/oxford.asp).

Wittchen, H.U., Robins, L.N., Cottler, L.B., Sartorius, N., Burke, J.D., Regier, D., 1991. Cross-cultural feasibility, reliability and sources of variance of the Composite International Diagnostic Interview (CIDI). The multicentre WHO/ADAMHA field trials. Br. J. Psychiatry: J. Ment. Sci. 645-653, 658, 159(Journal Article).

Woods, N.F., LaCroix, A.Z., Gray, S.L., Aragaki, A., Cochrane, B.B., Brunner, R.L. Masaki, K., Murray, A., Newman, A.B., 2005. Frailty: emergence and consequences in women aged 65 and older in the Women's Health Initiative observational study. J. Am. Geriatr. Soc. 53, 1321-1330, http://dx.doi.org/10. 1111/j.1532- 5415.2005.53405.x.

Ylli, A., Miszkurka, M., Phillips, S.P., Guralnik, J., Deshpande, N., Zunzunegui, M.V., 2016. Clinically relevant depression in old age: An international study with populations from Canada, Latin America and Eastern Europe. Psychiatry Res. 30 (241), 236-241, http://dx.doi.org/10.1016/j.psychres.2016.04.096. 